\title{
Şebekeye Bağlı Üç Adet Fotovoltaik Enerji Santralinin PVsyst Programı ile Analizi; Kilis Örneği
}

\author{
M.Sinan ÇINAROĞLU ${ }^{1 a^{*}}$, Mustafa NALBANTOĞLU ${ }^{1 b}$ \\ Kilis 7 Aralık Üniversitesi, Mühendislik-Mimarlık Fakültesi, Elektrik-Elektronik Mühendisliği Bölümü \\ Kilis / TÜRKIYE \\ sinanmcinaroglu@gmail.com
}

Received/Geliș: 20.01.2021

Accepted/Kabul: 25.02.2021

\begin{abstract}
Öz: Bu çalışmada; Kilis İlinde yer alan üç adet güneş enerjisi santrali ile PVsyst 7.1. simülasyon programında oluşturulan ve bahse konu santrallerle aynı özelliklere sahip sistemlerin analizleri yapılmıştır. PVsyst 7.1. simülasyon raporunda yer alan üretim verileri ile santrallere ait üç yıllık enerji üretim değerlerinin karşılaştırılması yapılmıştır. Ayrıca; santrallerin son üç yıllık üretim değerlerinin ortalaması EİGM verileri ile karşılaştırılmıştır. Bu santrallere ait panel ve inverter bilgileri ile santrallerin kurulduğu koordinatların yıllık ortalama sıcaklık ve ışınım verileri, PVsyst simülasyon programında kullanılmıştır. Santrallerin bulunduğu konumlara ait meteorolojik veriler, simülasyon programı veri tabanında yer alan Meteonorm 7.3. aracılığıyla sentetik olarak üretilmiştir. Analizi yapılan santraller; $1040 \mathrm{kWp}, 1029 \mathrm{kWp}$ ve $1000 \mathrm{kWp}$ kurulu güç değerlerine sahiptir. Analiz sonucunun daha iyi anlaşılabilmesi için santraller, birbirlerine yakın güç değerlerinde seçilmiş ve son üç yıla ait üretim verileri kullanılmıştır. Karşılaştırma neticesinde; elde edilen verilerin birbirlerine yakın ancak santral enerji üretim değerlerinin daha az olduğu görülmüştür. Meydana çıkan bu fark; hava şartlarına bağlı olarak değişen sıcaklık, bulutlu günlerin varlığı, gerçekleşen hava olaylarının tahmin edilememesi, panel üzerinde biriken kar, toz vb. sebeplerden kaynaklanmaktadır. Kilis ilinde bulunan ve üretim yapan santrallerin analizinin yapılması konusunda bu çalışma öncü durumdadır. Bu sebeple çalışmanın; bu alanda, Kilis İlinde yatırım yapmayı planlayan kişi ve/veya kurumlara yol gösterici olması amaçlanmaktadır.
\end{abstract}

Anahtar kelimeler: PVsyst; meteonorm; fotovoltaik enerji; Kilis.

\section{Analysis of Three Grid Connected Photovoltaic Power Plants with PVsyst Program; Sample of Kilis}

\begin{abstract}
In this study; energy production values of three photovoltaic power plants in Kilis City and created systems by PVsyst simulation program and having same characteristics with the said power plants were analyzed. Energy production data generated by the simulation report and the production data of the power plants for three years were compared. Also; the average data of the power plants for the last three years was compared with data of EIGM. Panel and inverter information of these power plants ant annual average temperature and radiation data of coordinates of the power plants were used in the PVsyst simulation program. Meteorological data of locations of the power plants were produced synthetically with Meteonorm 7.3. in the simulation program database. The plants analyzed; they have $1040 \mathrm{kWp}, 1029 \mathrm{kWp}$ and $1000 \mathrm{kWp}$ installed power values. To understand the analysis result well; the power plants were selected at close power values and production data for last three years were used. As a result of comparison, it was seen that the data obtained were close to each other but the power plants productions values were less. This difference; changing temperature depending on weather conditions, cloudy days, unimaginable weather events, snow, dust etc. accumulated on panels it is caused by the reason. The study; it is aimed to be a guide for people and institutions planning to invest in this field.
\end{abstract}

Keywords: PVsyst; meteonorm.; photovoltaic power plants; Kilis. 


\section{Giriş}

Yeryüzünde yaşamın sürdürülebilmesi için kuşkusuz ihtiyaç duyulan en önemli unsurlardan bir tanesi enerjidir. Nerede ve nasıl yaşanıldığına bakılmaksızın; hayatımız ve günlük davranışlarımız, enerji tüketiminden kazanılan yararlar ve girdiler ile çevrilmiştir. Yaşamın başlangıcından bu yana enerji birbirinden farklı kaynaklardan üretilmekte ve farklı şekillerde kullanılmaktadır [1,2].

Yaşadığımız yer kürede; azımsanmayacak oranda kullanılan fosil yakıt gereksiniminin azaltılmasında, yenilenebilir enerji kaynaklarının önemli rolü bulunmaktadır. Alternatif enerji kaynakları olarak ta bilinen yenilenebilir enerji kaynakları; güneş, rüzgâr, biokütle, hidrojen, hidrolik, jeotermal, dalga enerjisi olmak üzere doğada bol miktarda bulunan ve sürekliliği olan kaynaklardır [3].

Fosil yakıtların; doğamız ve insanoğlu için birçok olumsuz yönü bulunmaktadır. Hava kirliliğine, küresel ısınmaya, iklim değişikliklerine, oksijen miktarının azalmasına, karbondioksit oranının artmasına ve asit yağmurlarına sebep olmaları en büyük zararlarıdır. Bunlara ek olarak fosil yakıtlardan etrafa saçılan zehirli gazlar, insan sağlı̆̆ı üzerinde olumsuz etki bırakmaktadır [4].

Yapılan araştırmalar neticesinde; bilinen bütün kaynaklardan üretilebilecek enerji miktarı, güneşin sadece üç günde yaymış olduğu enerjiye eşittir [5]. Ayrıca; güneş enerjisini diğer alternatif enerji kaynaklarından bir adım ileriye taşıyan en önemli kazanımlarından biri ise çevreye karşı daha az zararlı oluşudur [6,7]. Güneş enerjisinden elektrik üretimi yaygın bir şekilde kullanılmaktadır. Fotovoltaik sistemler; güneş ışınlarını elektrik enerjisine doğrudan çeviren sistem elemanlarıdır [8].

Enerji ve Tabii Kaynaklar Bakanlığının hazırlayıp erişime sunduğu Türkiye Güneş Enerjisi Potansiyeli Atlası (GEPA) ile ülkemizin toplam yıllık güneşlenme süresi 2741 saat ve gelen güneş enerjisi $1527 \mathrm{kWh} / \mathrm{m}^{2} / \mathrm{y}$ ll olduğu bilinmektedir $[9,10]$.

Türkiye'de elektrik enerjisine duyulan gereksinim her yıl yaklaşık olarak $\% 5$ oranında artmaktadır. Yükselen enerji arzının bir kısmı güneş enerjisi sitemlerinden karşılanabilir. 2020 yılı itibariyle; güneş enerjisinden üretilen enerji miktarı 9249,8 GWh, kurulu güç ise 5995,2 $\mathrm{MWh}$ değerine ulaşmıştır. Ülkemizde; güneş enerjisi santrallerinin sayısı sürekli olarak artmasına rağmen, güneşten üretilen enerjinin payı, henüz istenilen seviyeye gelememiştir. Bunun ana sebebi; ilk kurulum maliyetlerinin yüksek oluşu ve geri ödeme süresinin çok uzun olduğu algısıdır [11,12]. Güneş enerjisi sistemlerine yapılacak yatırımlar için fizibilite çalışmalarının önceden oluşturulması büyük önem teşkil etmektedir. Günümüzde bu incelemeler ve araştırmalar bazı bilgisayar programları aracılığıla yapılabilmektedir [13].

Bu çalışmada; Kilis İlinde bulunan; 1040 kWp, 1029 kWp ve 1000 kWp kurulu güç değerlerinde olan; üç adet fotovoltaik enerji santralinin analizi PVsyst 7.1. simülasyon programı vasitasıla yapılmıştır. İlk olarak santrallerin bulunduğu konumlar programa tanıtılmış böylece sentetik olarak meteorolojik veriler elde edilmiştir. Daha sonra santrallerde kullanılan panel ve inverterler programda seçilmiştir. Santrallere ait gerekli tanımlamalar yapıldıktan sonra simülasyon gerçekleştirilmiştir. Simülasyon programının verdiği sonuç raporu üzerinden santrallere ait kayıpların ve üretim verilerinin analizi yapılmıştır. Analizi yapılan tesislerin, aktif olarak çalışan santraller olması sebebiyle bilgisayar analizleri ile gerçek üretim değerlerinin karşılaştırılması yapılmıştır. Karşılaştırma neticesini; sağlıklı ve gerçeğe daha yakın tutabilmek için bu üç santralin son üç yıllık üretim değerleri üzerinden analizleri yapılmıştır. Ayrıca santrallere ait üç yıllık üretim değerleri ile Enerji İşleri Genel Müdürlüğünün erişime sunduğu farklı fotovoltaik paneller ve alan büyüklüklerinde, yıllık olarak üretilebilecek enerji miktarları ve PVsyst sonuçları üzerinden karşılaştırılmıştır. 
PVsyst 7.1. simülasyon programı; Cenevre Üniversitesi tarafından geliştirilen; şebeke bağlantılı (on-grid), şebeke bağlantısız (off-grid) ve güneş enerjili sulama sistemleri gibi fotovoltaik enerji sistemlerinin tasarımlarının yapılıp sonuçlarının incelenmesi ve analizi amacıyla kullanılan ücretli bir simülasyon programıdır [14,15]. Bu program ile panel, inverter, santralin kurulacağı bölgeye ait ışıma ve meteorolojik veriler kullanılarak sisteme ait simülasyon sonucunda ayrıntılı bir rapor oluşturulur. Bu sayede kullanıcıyı, sistemden elde edilebilecek faydalar ve oluşabilecek kayıplar hakkında bilgilendirir [16,17].

Program hesaplamalarına ek olarak; birçok detayı da dâhil etmektedir. Bu detaylar; panel yıllık degradrasyon hesapları, kablolama detayları, bölgesel kirlilik durumları, detaylı güneş 1şınım verileri, gölgelenme detayları, albedo oranları, detaylı santral yerleşimleri ve şebeke analizi değerleridir $[18,19]$.

\section{Kilis İli İklim ve Güneş Radyasyon Değerleri}

Kilis ilinin iklimi; genel özellikleri bakımından Akdeniz İklimi bölgesinde kalmaktadır. Kilis; Akdeniz ve Karasal İklimin kesiştiği bölgede bulunduğundan iki iklimin de bazı özelliklerini göstermektedir. Ayrıca bulunduğu enlem ve boylam noktaları itibariyle güneşli gün sayısı oldukça yüksektir [20].

Şehir; yıllık ortalama 2975 saat (günlük 8,15 saat) güneşlenme süresine sahiptir. Kilis, Türkiye'de bu avantajı ile yüksek güneş enerjisi potansiyeline sahip bölgeler arasında bulunmaktadır [21]. 2020 yılı itibariyle, güneş enerjisi kurulu gücü yaklaşık olarak $8 \mathrm{MWh}$ ' dır. Kilis'te toplam 5 adet güneş enerjisi santrali bulunmakta ve yıllık yaklaşık olarak $11 \mathrm{GW}$ enerji üretmektedirler. İlaveten toplam kurulu gücü 13,86 GWh olan 5 adet fotovoltaik enerji santrali yapım aşamasındadır.

Enerji İşleri Genel Müdürlüğünün Güneş Enerjisi Potansiyel Atlası (GEPA) üzerinden Kilis iline ait küresel radyasyon değerleri Şekil 1a.'da, güneşlenme süresi ise Şekil 1b.'de sunulmuştur [22].

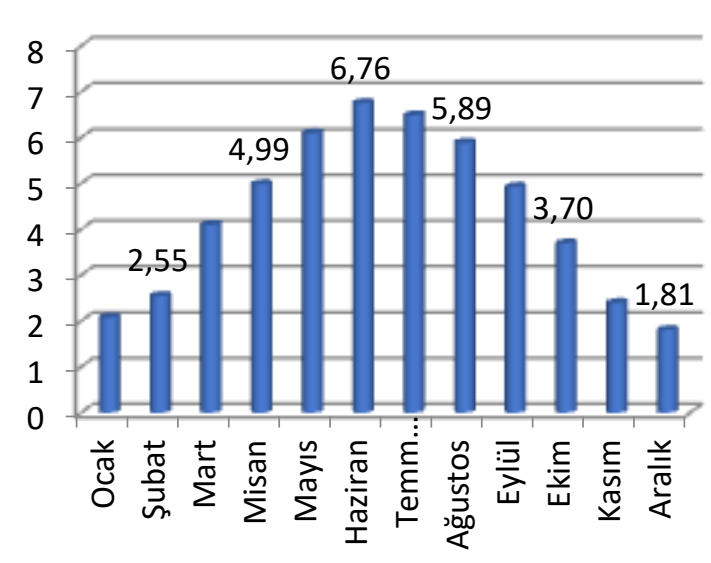

(a)

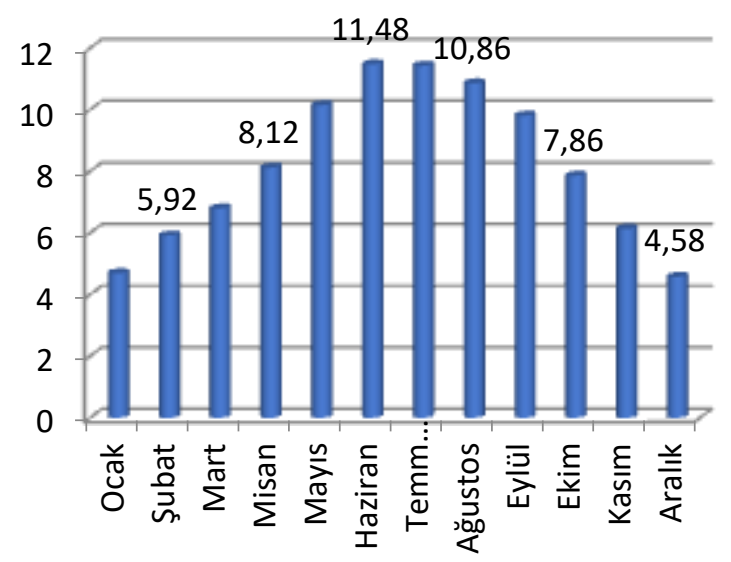

(b)

Şekil 1. Kilis küresel radyasyon değerleri $\left(\mathrm{kWh} / \mathrm{m}^{2}\right)$ ve güneşlenme süresi (saat)

Türkiye'de; en fazla güneşlenme süresine sahip bölge Güneydoğu Anadolu Bölgesidir [23]. Grafikler incelendiğinde Kilis ilinin fotovoltaik sistemler için oldukça elverişli durumda olduğu görülmektedir. Ancak; santral kurulumu için yer seçimi yapılmadan evvel dikkat edilmesi gereken bazı hususlar da bulunmaktadır. Bunlar; arazinin eğimi, toprak türü, güney yönüne olan cephesi, tarım arazisi olmaması ve ulaşım durumu gibi özelliklerdir. Ayrıca seçilecek arazilerin sanayi bölgesine ve enerji nakil hatlarına yakın olması büyük fayda sağlayacaktır. Santral etrafında 
gölgelemeye sebebiyet verebilecek herhangi bir ağaç, yapı vb. unsurun bulunmamasına dikkat edilmelidir [24,25].

\section{3. Şebekeye Bağlı Üç Adet Fotovoltaik Enerji Santralinin PVsyst Programı ile Analizi}

Simülasyon aşamasına geçmeden evvel PVsyst programına bir takım tanımlamaların yapılması gerekmektedir. İlk olarak santrallerin kurulduğu bölgelere ait 1şınım verileri programın veri tabanından alınmalıdır. Simülasyon programında yer alan coğrafi alan yönetim kısmında bölge haritadan işaretlenmelidir. Ancak analizi yapılacak santraller, coğrafi alan yönetim kısmında yer almadığından koordinat bilgileri programa elle girilmiştir. Programda yer alan Meteonorm 7.3. üzerinden girilen koordinat bilgilerine ait meteorolojik veriler sentetik olarak üretilmiştir. Sentetik verilerin teyidinin yapılması analizin daha sağlıklı bir sonuç vermesini sağlayacaktır. Teyit işlemi; Meteoroloji Genel Müdürlüğünün erişime sunduğu Türkiye Global Güneş Radyasyonu Uzun Yıllar Ortalaması [26] ve Enerji İşleri Genel Müdürlüğünün Güneş Enerjisi Potansiyel Atlası (GEPA) [22] üzerinden yapılmıştır. Tablo 1.' de Meteonorm 7.3. ile bu üç santrale ait üretilen sentetik veriler sunulmuştur. Şekil 2.' de PVsyst programı ile üretilen sentetik veriler ile GEPA ve MGM verilerinin karşılaştırılması yapılmıştır. Programa tanıtılan koordinat bilgileri, sırasıyla şöyledir:

1. Santral (Akdemir GES - $1040 \mathrm{kWp}) ; 37,3039^{\circ} \mathrm{E}-36,8269^{\circ} \mathrm{N}\left(20.000 \mathrm{~m}^{2}\right)$

2. Santral (Ataoğlu GES - $1029 \mathrm{kWp}) ; 37,1406^{\circ} \mathrm{E}-36,4752^{\circ} \mathrm{N}\left(17.800 \mathrm{~m}^{2}\right)$

3. Santral (Geylan Enerji GES - $1000 \mathrm{kWp}) ; 37,0717^{\circ} \mathrm{E}-36,8003^{\circ} \mathrm{N}\left(20.000 \mathrm{~m}^{2}\right)$

Tablo 1. Santraller için üretilen sentetik veriler $\left(\mathrm{kWh} / \mathrm{m}^{2} / \mathrm{y} 1 \mathrm{l}\right)$

\begin{tabular}{|c|c|c|c|c|c|c|c|c|c|c|c|c|}
\hline Aylar & ర్ & ڤ્ڤ & $\stackrel{ \pm}{E}$ & 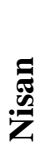 & $\sum_{i}^{\infty}$ & 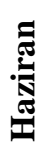 & 氖 & 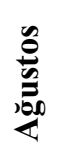 & 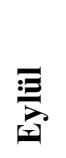 & $\frac{\Xi}{\frac{1}{x}}$ & 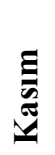 & 兰 \\
\hline $\begin{array}{c}\text { Akdemir } \\
\text { GES }\end{array}$ & $\vec{n}$ & $\begin{array}{l}\vec{\sigma} \\
\text { ते }\end{array}$ & \begin{tabular}{l}
$\tilde{\gamma}$ \\
\multirow{\sigma}{*}{}
\end{tabular} & $\begin{array}{l}\infty \\
\infty \\
\text { in }\end{array}$ & $\begin{array}{l}\text { No } \\
\text { 0. }\end{array}$ & $\overrightarrow{0}$ & $\hat{\Omega}$ & $\stackrel{0}{\pi}$ & $\hat{\theta}^{\circ}$ & $\stackrel{m}{\stackrel{m}{\sigma}}$ & $\underset{\delta}{\sigma}$ & $\vec{n}$ \\
\hline $\begin{array}{c}\text { Ataoğlu } \\
\text { GES }\end{array}$ & $\begin{array}{l}n \\
0 \\
i\end{array}$ & $\overrightarrow{\widehat{\sigma}}$ & $\stackrel{\infty}{\underset{\sigma}{*}}$ & $\underset{\dot{v}}{\dot{v}}$ & $\frac{n}{6}$ & $\underset{\substack{\infty \\
\sim}}{\stackrel{\infty}{+}}$ & $\stackrel{\sim}{\sim}$ & $\frac{n}{6}$ & 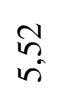 & $\begin{array}{l}\infty \\
0 \\
\forall\end{array}$ & $\begin{array}{l}\vec{\infty} \\
i\end{array}$ & $\stackrel{\text { co }}{\text { in }}$ \\
\hline $\begin{array}{c}\text { Geylan } \\
\text { Enerji } \\
\text { GES }\end{array}$ & $\vec{a}$ & $\begin{array}{l}\text { के } \\
\text { तi }\end{array}$ & \begin{tabular}{l}
$\stackrel{\sim}{\sigma}$ \\
\multirow{\sigma}{*}{}
\end{tabular} & $\begin{array}{l}\text { రె } \\
\text { in }\end{array}$ & $\frac{n}{6}$ & $\stackrel{m}{\sim}$ & $\begin{array}{l}\bar{\sigma} \\
\sim\end{array}$ & $\hat{\sigma}$ & $\frac{2}{i n}$ & $\frac{9}{f}$ & $\bar{a}$ & $\frac{n}{i}$ \\
\hline
\end{tabular}

Şekil 2. incelendiğinde Meteonorm 7.3. ile üretilen sentetik verilerin gerçeğe yakın olduğu görülmektedir. Bu durum; PVsyst simülasyon programının, güvenilir olduğunu gösterir en önemli parametrelerden biridir.

Fotovoltaik panellerin dezavantajlarından bir tanesi de verimlerinin düşük olmasıdır. Paneller, farklı üretim teknikleriyle ve çeşitli malzemelerden üretilmeleri sayesinde; verimlerinde her geçen gün kayda değer artış gözlenmektedir. Ancak şu an ki teknolojik durum ile bir panelin verimi \%15-21 arasında değişmektedir. Optik yoğunlaştırıcılar kullanıldığında ise verim de \%35'e kadar ulaşılmıştır [27,28]. Bu olumsuzluğu bir nebze olsun telafi edebilmek adına, santral verimini arttıracak farklı yöntemlerin geliştirilmesi gerekmektedir. Bu yöntemlerin başında ise panel eğim ve azimut açıların doğru seçilmesi gelmektedir. Panel ve azimut açılarının doğru seçilmesi ile 1şımadan maksimum seviyede yararlanılmaktadır [29].

Çalışmada yer alan santrallerin panel eğim açıları $30^{\circ}$ azimut açıları ise $0^{\circ}$ dir. PVsyst simülasyon programında oluşturulan sistemlerin panel eğim ve azimut açıları santrallerle aynı olacak şekilde tanımlanmıştır. 


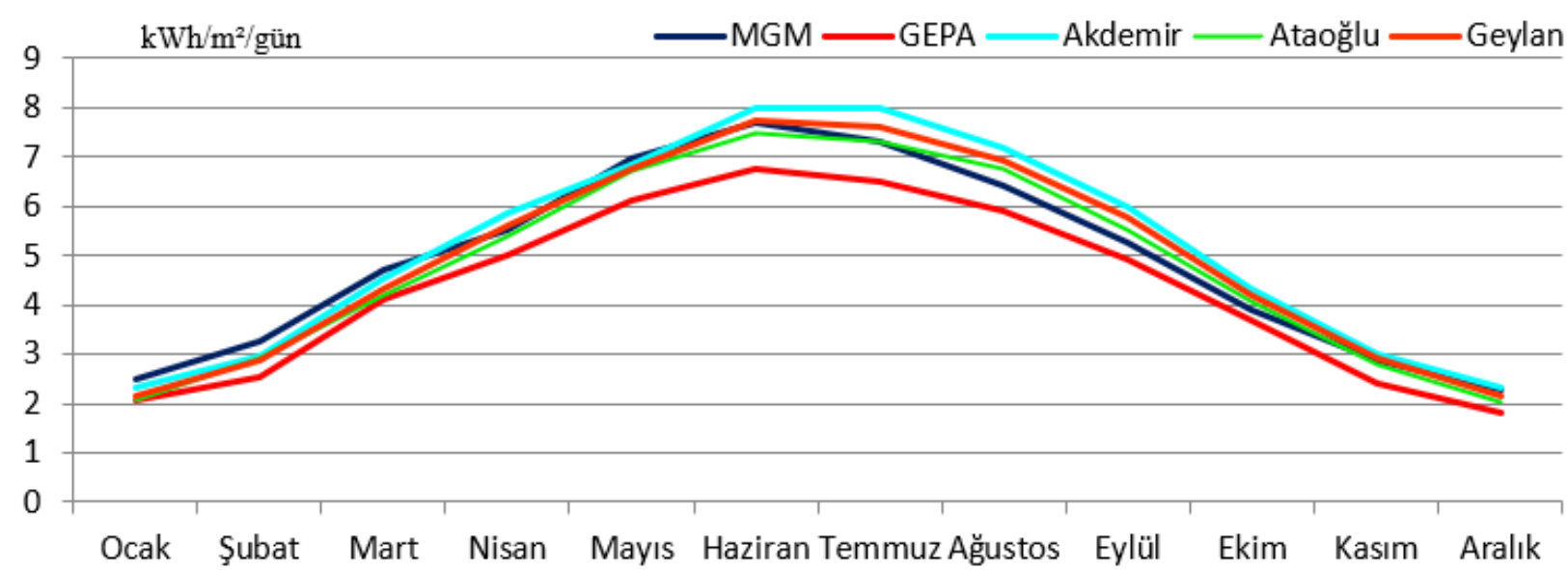

Şekil 2. Meteonorm 7.3. ile üretilen sentetik verilerin MGM ve GEPA ile karş1laştırılması

Programın veri tabanında birçok firmaya ait panel, inverter, akü vb. sistem elemanlarının elektriksel ve mekaniksel verileri bulunmaktadır. Tanıtılacak sistem elemanları programın veri tabanında yer almıyorsa elle bu bilgiler tanımlanabilmektedir [30]. Çalışmanın amacı, analizi yapılan santrallerle aynı özelliklerde sistem oluşturmak olduğundan üç santralde kullanılan panel ve invertere ait marka ve modeller PVsyst programına tanıtılmıştır. Santrallerde kullanılan panel ve inverter bilgileri şu şekildedir:

1. Akdemir GES:

Panel; Solarturk Energy marka, poly 255w 60 cells (Polikristal) 4080 adet

İnverter; ABB marka, TRIO-27 6TL-OUTd-S1-US 34 adet

2. Ataoğlu GES:

Panel; Voltec Solar marka, VSPS-260-60-A (Polikristal) 3957 adet

İnverter; Socomec marka, SUNSYS B10 42 adet

3. Geylan Enerji GES:

Panel; CEEG marka, SST 280-72M (Monokristal) 3600 adet

İnverter; Huawei Technologies marka, Sun2000-33KTL-A 26 adet

Simülasyon programında, santralin bulunduğu bölge için gölgelenmeye sebep olabilecek yapı, ağaç vb. elemanların gölgeleme analizini yapmak mümkündür. Bu analiz için programda gölgelenmeye sebep olabilecek elemanların 3D çizimleri yapılabilmektedir. Ancak çalışmada yer alan santrallerin yakınlarında gölge sağlayacak yapı, ağaç vb. bulunmadığından bu parametre tanımlanmamıştır.

Sistem tasarımı için gerekli olan tüm tanımlamalar doğru bir şekilde yapıldıktan sonra PVsyst programı; simülasyona hazır olunduğuna dair uyarı verir. Simülasyon sonucunda oluşan raporda; sistem bileşenleri, ışınım miktarı, üretim durumu ve kayıp diyagramı yer almaktadır. Program tarafından verilen santrallere ait kayıp diyagramları; Şekil 3a. (Akdemir GES), Şekil 3b. (Ataoğlu GES) ve Şekil 3c. (Geylan Enerji GES)'de sunulmuştur.

Programa ait kayıp diyagramları incelendiğinde santrallerin bulundukları konumlara gelen ışınım miktarları görülmektedir. Paneller, düz bir zemine yerleştirilmiş olup etraflarında herhangi bir gölgeleme yapacak ağaç, bina vb. unsur bulunmadığından gölgeleme sebepli bir kayıp söz konusu değildir [31,32].

Güneş panellerinin karakteristik özelliklerinden kaynaklı bazı kayıplardan söz edilebilir [33]. Fotovoltaik panellerin çalışma esasları belirlenirken standart test koşulları $\left(25^{\circ} \mathrm{C}\right.$ sıcaklık, 1000 
$\mathrm{Wh} / \mathrm{m}^{2}$ ışıma [34]) altında ki performansları temel alınmaktadır. Dolayısıyla yüksek sıcaklık ve düşük 1şıma değerlerinden kaynaklanan kayıplar meydana gelmektedir.

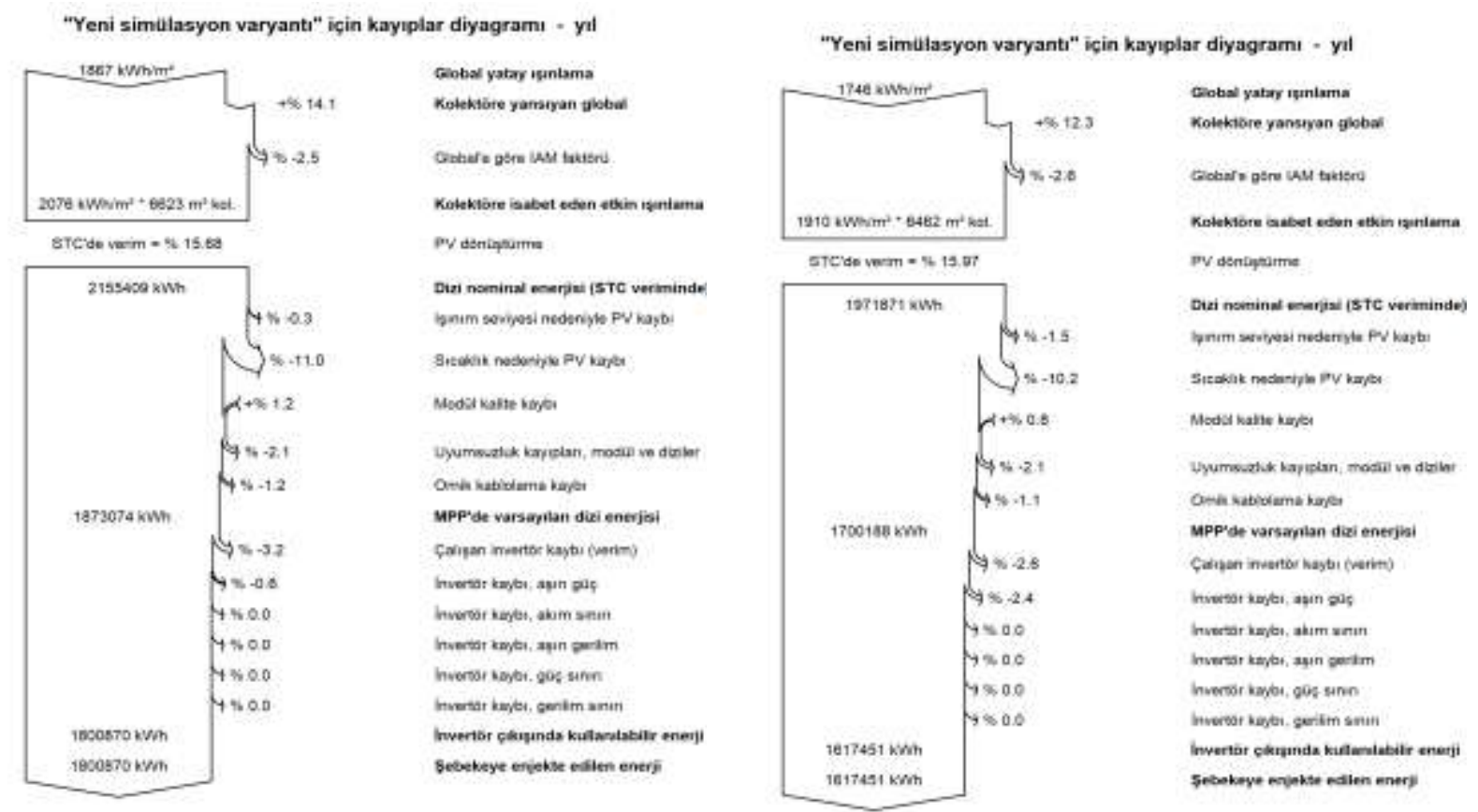

(a)

(b)

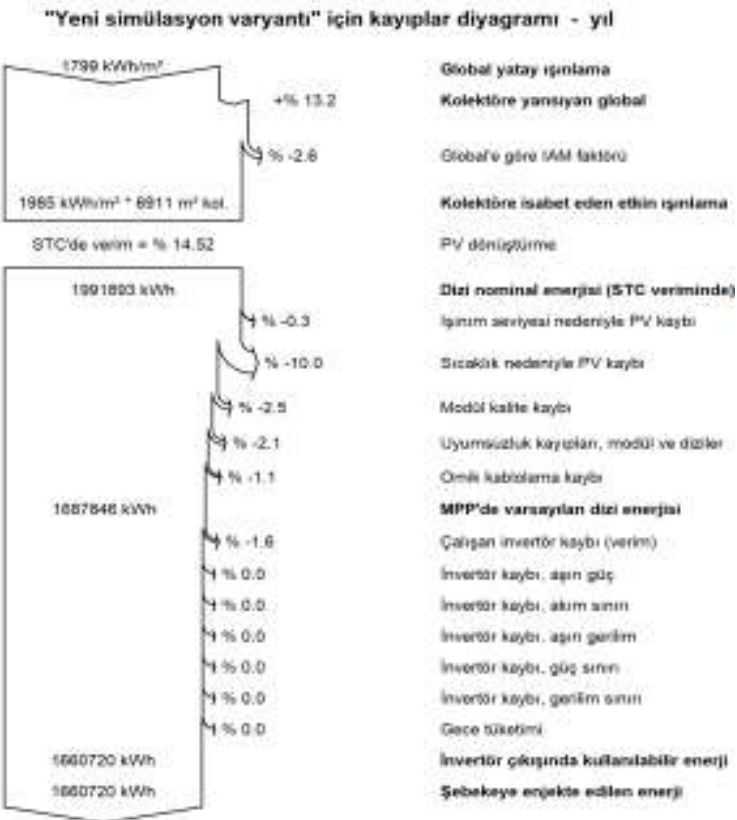

(c)

Şekil 3. Santrallere ait kayıp diyagramları

Mismatch kayıpları olarak ta bilinen uyumsuzluk kayıpları; güneş enerjisi santrallerinde bulunan her bir panelin ürettiği enerjinin eşit olmaması durumunda oluşmaktadır. Panel sayısının arttığ1 uygulamalarda bu kayıp miktarı da artmaktadır [35,36]. Santrallere ait kayıp diyagramlarında uyumsuzluk kayıları görülmektedir.

Kayıp diyagramı incelendiğinde panele yansıyan ışıma ile üretilebilecek enerjiden tüm kayıplar düştükten sonra şebekeye verilecek nihaî enerji miktarı görülmektedir. Ayrıca simülasyon sonucu oluşan analiz raporunda, santrallere ait aylık ve yıllık üretim verileri yer almaktadır. 
Santrallerin 2018, 2019 ve 2020 y1llarına ait üretim değerleri ile simülasyon programında hesaplanan üretim verileri Tablo 2.' de bu iki durumun karşılaştırılması ise Akdemir GES için Şekil 4a., Ataoğlu GES için Şekil 4b. ve Geylan Enerji GES için Şekil 4c.' de verilmiştir.
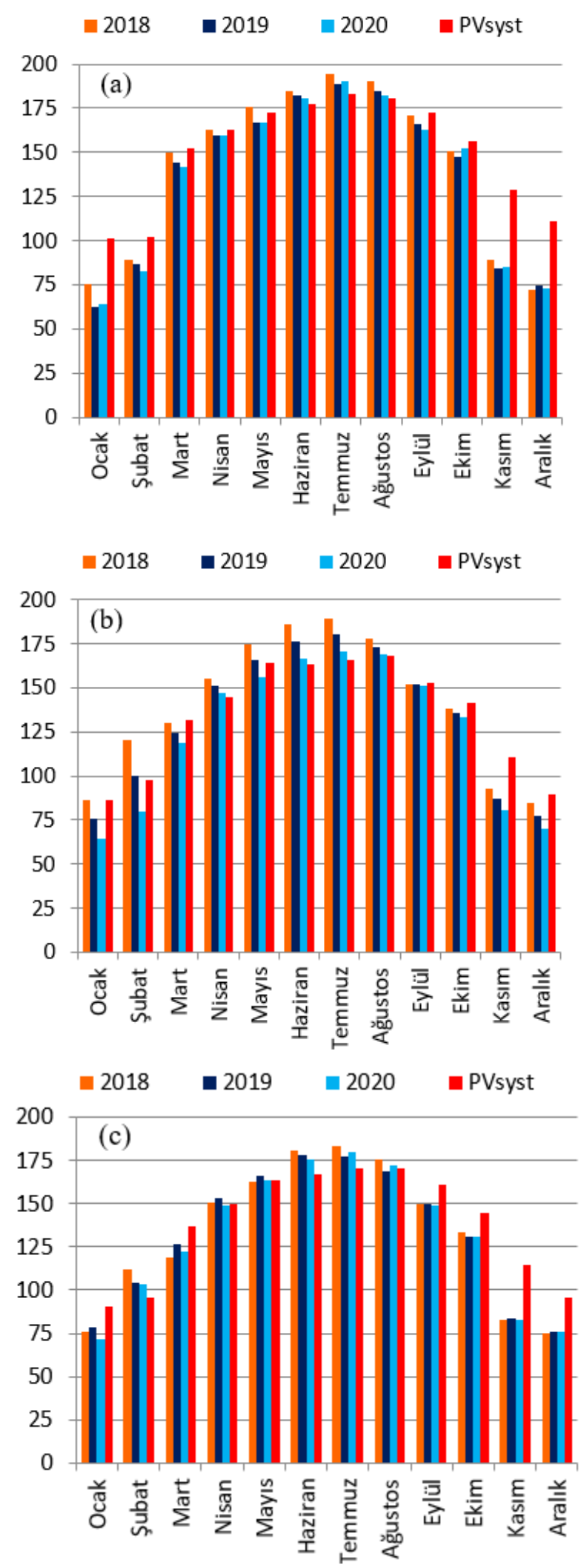

Şekil 4. a. Akdemir GES, b.Ataoğlu GES, c. Geylan Enerji GES santrallere ait üç yıllık $(2018,2019$ ve 2020 yıllarına ait) üretim değerleri ile PVsyst verilerinin karşılaştırılması 
Şekil 5.' te Enerji İşleri Genel Müdürlüğünün erişime sunduğu farklı fotovoltaik paneller ve alan büyüklüklerinde, yıllık olarak üretilebilecek enerji miktarlarını gösterir grafik verilmiştir [37]. Grafik incelendiğinde Kilis İli için monokristal fotovoltaik panel ile daha fazla enerji üretilebileceği görülmektedir.

Tablo 2. Santrallerin son üç yıllık üretim değerleri ve PVsyst Ürettim verileri

\begin{tabular}{|c|c|c|c|c|c|c|c|c|c|c|c|c|}
\hline \multirow{3}{*}{ Aylar } & \multicolumn{4}{|c|}{ Akdemir GES } & \multicolumn{4}{|c|}{ Ataoğlu GES } & \multicolumn{4}{|c|}{ Geylan Enerji GES } \\
\hline & \multicolumn{3}{|c|}{ Gerçek Üretim } & \multirow[b]{2}{*}{ PVsyst } & \multicolumn{3}{|c|}{ Gerçek Üretim } & \multirow[b]{2}{*}{ PVsyst } & \multicolumn{3}{|c|}{ Gerçek Üretim } & \multirow[b]{2}{*}{ PVsyst } \\
\hline & $\stackrel{\infty}{\stackrel{\sim}{\sim}}$ & $\stackrel{\partial}{\stackrel{\nu}{\nu}}$ & ণ્ડి & & $\stackrel{\infty}{\stackrel{\sim}{\sim}}$ & $\frac{a}{\stackrel{\sigma}{c}}$ & $\begin{array}{l}\text { ઠิ } \\
\text { రิ }\end{array}$ & & $\stackrel{\infty}{\stackrel{\sim}{\sigma}}$ & $\stackrel{\vec{\nu}}{\stackrel{\sim}{2}}$ & 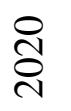 & \\
\hline Ocak & $\stackrel{n}{2}$ & $\begin{array}{l}\text { I1 } \\
\text { î }\end{array}$ & $\begin{array}{l}\hat{\infty} \\
\hat{\sigma}\end{array}$ & $\stackrel{m}{\sigma}$ & $\begin{array}{l}n \\
n \\
\infty \\
\infty\end{array}$ & $\begin{array}{l}\vec{n} \\
\sim\end{array}$ & $\begin{array}{l}n \\
n \\
f\end{array}$ & $\begin{array}{l}\text { @i } \\
\infty\end{array}$ & $\begin{array}{l}n \\
\infty \\
\infty\end{array}$ & $\begin{array}{l} \pm \\
\infty \\
\infty \\
\infty\end{array}$ & $\stackrel{\hat{\sigma}}{*}$ & $\overrightarrow{8}$ \\
\hline Şubat & $\begin{array}{l}\stackrel{\infty}{2} \\
\text { مे }\end{array}$ & 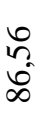 & $\begin{array}{l}\mathbb{N} \\
\text { î }\end{array}$ & $\begin{array}{l}\infty \\
\stackrel{0}{0}\end{array}$ & 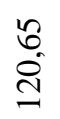 & $\frac{n}{8}$ & 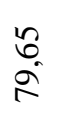 & $\frac{a}{a}$ & $\begin{array}{l}\tilde{\sigma} \\
\text { I } \\
=\end{array}$ & $\begin{array}{l}\stackrel{+}{n} \\
\stackrel{+}{0}\end{array}$ & $\begin{array}{l}\stackrel{0}{n} \\
\stackrel{n}{0}\end{array}$ & $\begin{array}{l}\infty \\
\tilde{n}\end{array}$ \\
\hline Mart & $\begin{array}{l}\stackrel{2}{\tilde{a}} \\
\stackrel{a}{-}\end{array}$ & $\begin{array}{l} \pm \\
\dot{J} \\
\dot{J}\end{array}$ & $\begin{array}{l}\text { ¿ } \\
\text { I } \\
\text { I }\end{array}$ & $\begin{array}{l}0 \\
\hat{i} \\
\end{array}$ & 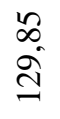 & $\begin{array}{l}\tilde{m} \\
\stackrel{\Xi}{\Xi}\end{array}$ & $\begin{array}{l}n \\
\infty \\
\infty \\
=\end{array}$ & $\overrightarrow{\tilde{d}}$ & $\begin{array}{l}\infty \\
\infty \\
= \\
=\end{array}$ & 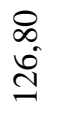 & 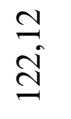 & $\overrightarrow{\vec{m}}$ \\
\hline Nisan & $\begin{array}{l}\infty \\
0 \\
\hat{\tilde{j}} \\
\underline{1}\end{array}$ & $\begin{array}{l}\text { ơ } \\
\text { ô } \\
\text { ñ }\end{array}$ & $\begin{array}{l}n \\
\infty \\
\infty \\
0\end{array}$ & $\hat{\tilde{\sigma}}$ & $\begin{array}{l}\text { જ } \\
\stackrel{\Delta}{n}\end{array}$ & $\begin{array}{l}\partial \\
\hat{B}\end{array}$ & $\begin{array}{l}\text { જे } \\
\text { ঠे } \\
\text { I }\end{array}$ & $\begin{array}{l}0 \\
\dot{J} \\
\text { J }\end{array}$ & $\frac{\Delta}{0}$ & $\begin{array}{l}n \\
\hat{n} \\
n\end{array}$ & $\begin{array}{l}\text { જे } \\
\infty \\
\text { I }\end{array}$ & $\begin{array}{l}n \\
\stackrel{n}{n} \\
\end{array}$ \\
\hline Mayıs & 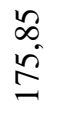 & $\begin{array}{l}\underline{\sigma} \\
\hat{\sigma}\end{array}$ & $\begin{array}{l}\frac{\pi}{6} \\
\stackrel{0}{0}\end{array}$ & $\begin{array}{l}\infty \\
\stackrel{1}{\Sigma} \\
\underline{I}\end{array}$ & 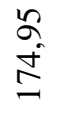 & $\begin{array}{l}\mathfrak{a} \\
\tilde{b}\end{array}$ & $\begin{array}{l}\bar{m} \\
\text { s. } \\
\end{array}$ & $\begin{array}{l}+ \\
\stackrel{+}{ \pm}\end{array}$ & 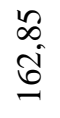 & $\begin{array}{l}2 \\
0 \\
0 \\
0\end{array}$ & $\begin{array}{l}\tilde{n} \\
\hat{\sigma} \\
\sigma\end{array}$ & $\begin{array}{l}\infty \\
\hat{\sigma}\end{array}$ \\
\hline Haziran & $\begin{array}{l}\stackrel{2}{a} \\
\dot{\infty} \\
=\end{array}$ & $\begin{array}{l}\text { \& } \\
\text { i } \\
\infty\end{array}$ & $\begin{array}{l}0 \\
\stackrel{0}{0} \\
\infty \\
0\end{array}$ & $\begin{array}{l}\infty \\
\stackrel{\infty}{\Sigma}\end{array}$ & $\begin{array}{l}\hat{\sigma} \\
\tilde{\sigma}\end{array}$ & $\begin{array}{l}\stackrel{?}{+} \\
\stackrel{\sigma}{-} \\
\end{array}$ & $\begin{array}{l}\dot{a} \\
\text { ô } \\
0\end{array}$ & $\overrightarrow{\hat{\sigma}}$ & $\begin{array}{l}\circ \\
\stackrel{0}{0} \\
\infty\end{array}$ & $\begin{array}{l}\stackrel{\cap}{n} \\
\infty \\
\text { D } \\
=\end{array}$ & $\begin{array}{l}\infty \\
\infty \\
\\
=\end{array}$ & $\begin{array}{l}\hat{b} \\
\text { }\end{array}$ \\
\hline Temmuz & 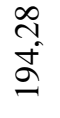 & $\begin{array}{l}\bar{a} \\
\infty \\
\infty\end{array}$ & 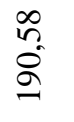 & $\begin{array}{l}\hat{a} \\
\infty \\
\infty\end{array}$ & $\begin{array}{l}\sqrt{n} \\
\stackrel{\infty}{=}\end{array}$ & $\begin{array}{l}8 \\
\stackrel{0}{\circ} \\
\infty\end{array}$ & 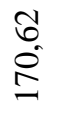 & in & $\begin{array}{l}n \\
\infty \\
\infty \\
-\infty\end{array}$ & 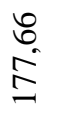 & $\begin{array}{l}\hat{\sigma} \\
\hat{\Omega}\end{array}$ & $\stackrel{0}{\stackrel{0}{\Omega}}$ \\
\hline Ağustos & $\begin{array}{l}\stackrel{0}{\varrho} \\
\stackrel{2}{2}\end{array}$ & $\begin{array}{l}\mathscr{n} \\
\stackrel{+}{\infty} \\
\infty\end{array}$ & $\begin{array}{l}= \\
\underset{\infty}{0}\end{array}$ & $\begin{array}{l}\infty \\
\stackrel{\infty}{\infty}\end{array}$ & $\begin{array}{l}\stackrel{2}{\infty} \\
\stackrel{\infty}{=}\end{array}$ & $\begin{array}{l}\stackrel{n}{n} \\
\text { s } \\
\underline{n}\end{array}$ & $\begin{array}{l}2 \\
\hat{\infty} \\
0 \\
0\end{array}$ & $\begin{array}{l}n \\
\infty \\
\infty \\
0\end{array}$ & $\begin{array}{l}\hat{n} \\
\hat{n}\end{array}$ & $\begin{array}{l}n \\
n \\
\infty \\
0 \\
0\end{array}$ & 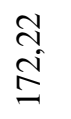 & $\begin{array}{l}0 \\
\stackrel{0}{\Omega}\end{array}$ \\
\hline Eylül & $=$ & $\begin{array}{l}\text { ले } \\
\text { ठ̊ }\end{array}$ & $\begin{array}{l}\infty \\
0 \\
\hat{\sigma}\end{array}$ & $\hat{\hat{I}}$ & 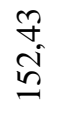 & $\frac{\sigma}{n}$ & $\frac{\mathfrak{m}}{\stackrel{\check{n}}{=}}$ & $\begin{array}{l}\hat{\imath} \\
\hat{n}\end{array}$ & $\begin{array}{l}\stackrel{1}{0} \\
\stackrel{0}{n}\end{array}$ & $\begin{array}{l}g \\
\text { gे } \\
\text { g }\end{array}$ & $\begin{array}{l}\infty \\
\infty \\
\infty \\
\stackrel{\infty}{ \pm}\end{array}$ & $\stackrel{\hat{\theta}}{\hat{\theta}}$ \\
\hline Ekim & $\begin{array}{l}\stackrel{\text { m }}{2} \\
\stackrel{n}{n}\end{array}$ & $\frac{\vec{N}}{\frac{\mathfrak{J}}{\Xi}}$ & $\begin{array}{l}\tilde{N} \\
\text { ñ } \\
\end{array}$ & $\begin{array}{l}0 \\
\varnothing \\
ٌ\end{array}$ & $\begin{array}{l}\dot{v} \\
\infty \\
\infty \\
\end{array}$ & 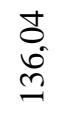 & $\begin{array}{l}n \\
m \\
m\end{array}$ & $\begin{array}{l}0 \\
\dot{J} \\
\dot{J}\end{array}$ & $\overrightarrow{\tilde{m}}$ & $\begin{array}{c}\stackrel{\infty}{\sim} \\
\stackrel{-}{=}\end{array}$ & $\begin{array}{l}\tilde{n} \\
\stackrel{2}{2} \\
=\end{array}$ & $\begin{array}{l}\stackrel{+}{ \pm} \\
\stackrel{+}{ \pm}\end{array}$ \\
\hline Kasim & $\begin{array}{l}\infty \\
2 \\
\infty \\
\infty\end{array}$ & $\begin{array}{l}\text { ले } \\
\dot{\infty}\end{array}$ & $\begin{array}{l}f \\
\dot{\infty} \\
\infty\end{array}$ & 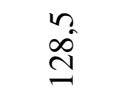 & $\begin{array}{l}\text { ă } \\
\hat{~}\end{array}$ & $\begin{array}{l}n \\
\hat{\infty} \\
\infty\end{array}$ & $\begin{array}{l}\stackrel{2}{0} \\
\stackrel{\infty}{\infty}\end{array}$ & $\begin{array}{l}\infty \\
\stackrel{0}{\Xi}\end{array}$ & $\begin{array}{l}\tilde{n} \\
\text { ô } \\
\infty\end{array}$ & $\underset{\infty}{\stackrel{+}{\infty}}$ & \begin{tabular}{l}
$n$ \\
\multirow{\infty}{n}{} \\
$\infty$
\end{tabular} & $\begin{array}{l}\stackrel{0}{ \pm} \\
\stackrel{\Xi}{=}\end{array}$ \\
\hline Aralık & 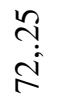 & $\begin{array}{l}\bar{J} \\
\stackrel{+}{\mathbb{N}}\end{array}$ & $\stackrel{m}{\stackrel{m}{2}}$ & $\begin{array}{l}\stackrel{0}{\Xi} \\
\Xi\end{array}$ & $\begin{array}{l}\infty \\
\infty \\
\dot{\infty}\end{array}$ & $\begin{array}{l}\stackrel{n}{n} \\
\stackrel{2}{\Sigma}\end{array}$ & $\begin{array}{l}\infty \\
\infty \\
8\end{array}$ & $\begin{array}{l}0 \\
\stackrel{\infty}{\infty}\end{array}$ & $\begin{array}{l} \pm \\
\stackrel{\mathbb{N}}{+}\end{array}$ & $\frac{m}{2}$ & 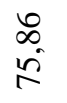 & $\begin{array}{l}0 \\
\ddot{2}\end{array}$ \\
\hline Toplam & 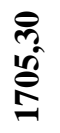 & \begin{tabular}{l} 
Ñ \\
\multirow{2}{*}{} \\
\multirow{2}{0}{}
\end{tabular} & 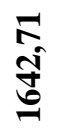 & 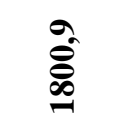 & 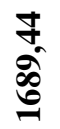 & 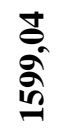 & 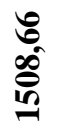 & $\frac{12}{6}$ & $\begin{array}{l}\text { ले } \\
\stackrel{8}{8}\end{array}$ & $\begin{array}{l}\text { ले } \\
\text { से } \\
\text { in }\end{array}$ & $\begin{array}{l}\text { 足 } \\
\text { ñ } \\
\stackrel{n}{n}\end{array}$ & 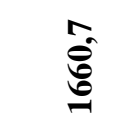 \\
\hline
\end{tabular}




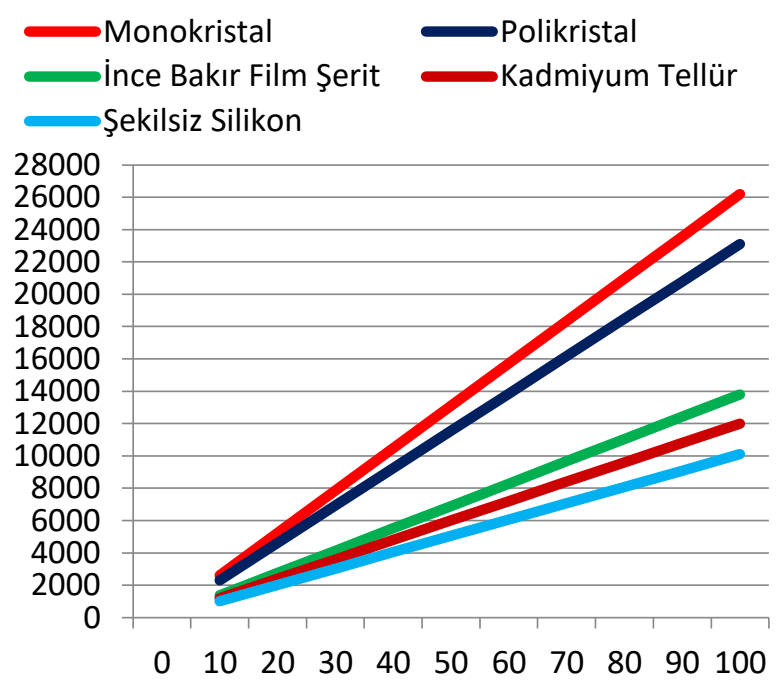

Şekil 5. PV panel tipi - alan - üretilebilecek enerji miktarı

Analizi yapılan santraller; Akdemir GES, Ataoğlu GES tesislerinde polikristal, Geylan Enerji GES tesisinde ise monokristal paneller kullanılmıştır. Analizin daha sağlık bir sonuç verebilmesi için santrallere ait 3 yıllık üretim değerleri, PVsyst simülasyon programı sonuçları ve Enerji İşleri Genel Müdürlüğü (EİGM) verilerinin karşılaştırılması sırasıyla Şekil 6a. (Akdemir GES), şekil 6b. (Ataoğlu GES) ve şekil 6c. (Geylan Enerji GES)' de sunulmuştur.
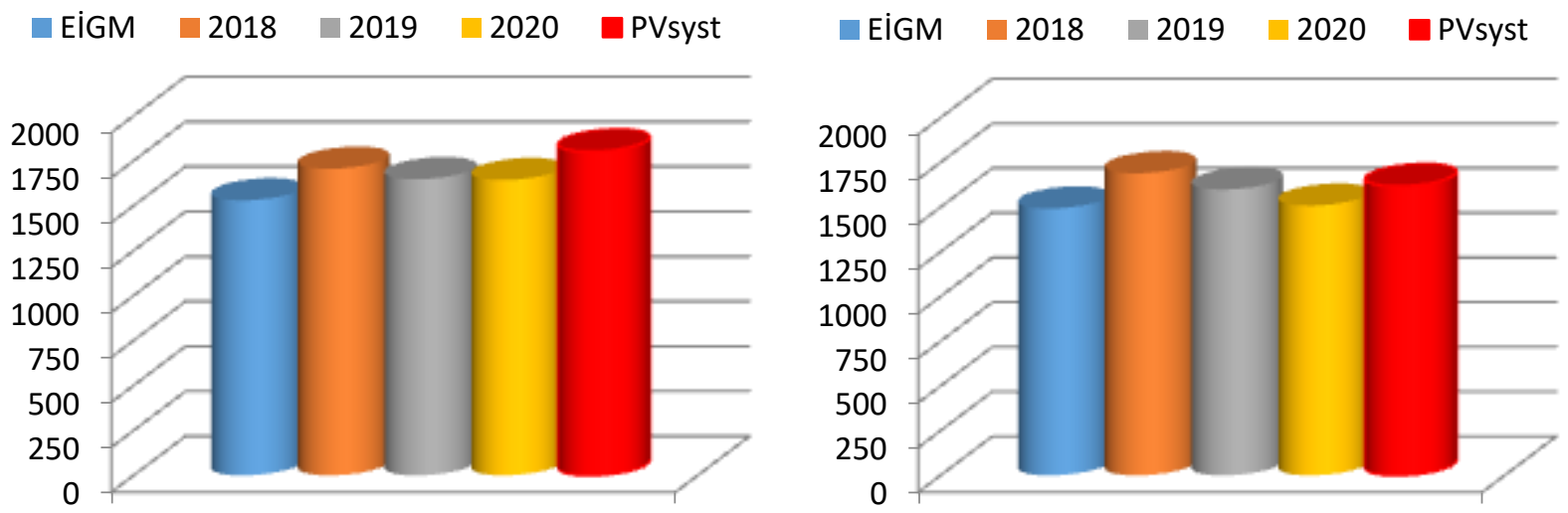

(a)

(b)

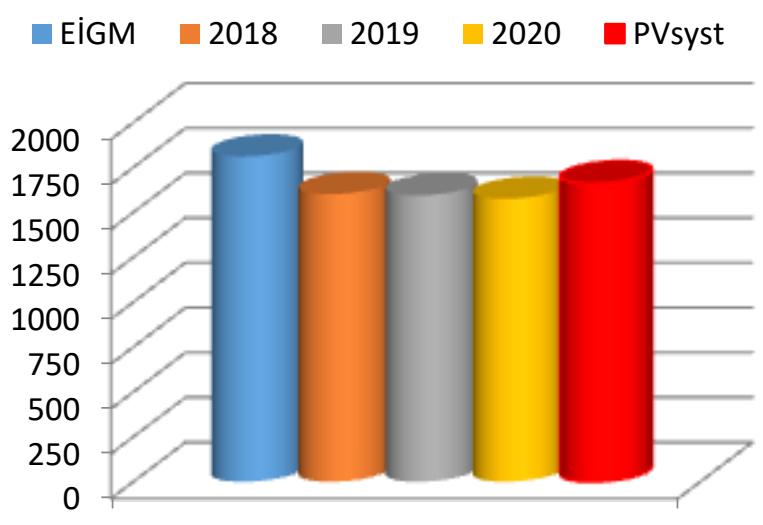

(c)

Şekil 6. Santrallere ait üç yıllık üretim değerleri ile EİGM verileri ve PVsyst sonuçlarının karşılaştırılması (MWh/yıl) 
Santrallere ait üç yıllık ortalama üretim değerleri ile PVsyst ve EİGM tahmini üretim verileri karş1laştırılmıştır. Böylece; Akdemir GES için PVsyst \%8,15 daha fazla, EİGM \%8,11 daha az; Ataoğlu GES için PVsyst \%1,34 daha fazla, EİGM \%6,47 daha az ve Geylan Enerji GES için PVsyst \%4,41 daha fazla, EİGM \%13,84 daha fazla enerji üretilebileceği tahmin edilmektedir. Geylan Enerji GES için EİGM tahmini üretim verisinin daha fazla olduğu görülmektedir. EİGM verisi, Kilis için ortalama bir değerdir. EİGM ile yapılan tahminde santralin bulunduğu konum, santralde kullanılan panel, inverter marka ve verimleri, panellerin eğim ve azimut açıları ile kirlilik durumu gibi parametreler kullanılmamaktadır [38,39]. Dolayısı ile PVsyst tahmini EIGGM tahmininden daha hassas ve gerçeğe daha yakındır. Bu durum, grafiklerde kolaylıkla görülmektedir.

Grafikler incelendiğinde; santrallere ait üç yıllık üretim değerlerinin, PVsyst için ve EİGM tahmini verilerine yakın olduğu görülmektedir. Akdemir GES ve Ataoğlu GES santralleri için EİGM tahmini verileri PVsyst sonuç değerinden düşüktür. Ancak Geylan Enerji GES santralinde EİGM tahmini verileri PVsyst sonuç değerinden yüksektir. Bu duruma sebep olabilecek birçok durum söz konusu olabilir. Muhtemel sebeplerden bir tanesi ise PVsyst programında, santralde kullanılan panellere ait marka ve model tanımlanmaktadır. Bu durumda santralde kullanılan panellerin kalitesi; verimi dolayısıyla üretim değerini büyük ölçüde etkilemektedir [40,41]. Santrallerde kullanılan panellerin farklı marka ve kalitede olması, panel temizliğine gerekli özenin gösterilmemesi vb. durumlar, verimin azalmasına dolayısıyla santrallerden beklenen üretim değerinin düşmesine sebep olmaktadir $[42,43]$.

\section{Sonuç ve Öneriler}

Tablolar ve grafikler incelendiğinde; santrallere ait üretim değerlerinde yıllar arasında değişiklikler gözlemlenmektedir. Bu duruma sebep olabilecek birçok durum bulunmaktadır. Panel verimleri her yıl biraz daha azalmaktadır. Dolayısıyla üretim miktarı, takip eden yıllarda düşmektedir. Bununla birlikte mevsimsel farklılıklar üretim değerinin belirlenmesinde önemli bir parametredir. Söz gelimi; bulutsuz ve güneşli günlerin fazla olduğu kış aylarında, üretim artmaktadır. Başka bir durumda ise aşırı sıcak geçen yaz aylarında, 1sı kaynaklı kayıplar oluşabileceğinden üretim azalmaktadır.

Santrallere ait üç yıllık üretim değerleri ile PVsyst simülasyon programında hesaplanan üretim tahminleri gerçek değerden sapması \%10'un altında kaldığ 1 gözlemlenmiştir. EİGM verilerine göre yapılan tahmini üretim değerlerinin ise \%1'un üzerinde sapma gösterdiği gözlemlenmiştir. Ancak; ortaya çıkan farklılıklara sebep olabilecek durumlar ise hava şartlarına bağlı olarak değişen sıcaklık, bulutlu gün sayısının tahmin edilenden farklılık göstermesi, hava olaylarının tahmin edilen ile aynı olmaması, panel üzerinde biriken kar, toz vb. yabancı maddelerin varlığı ve panel temizliğine dikkat edilmemesi gibi etkenler olabilmektedir.

$\mathrm{Bu}$ farklılıklara rağmen; üretim anlamında gerçeğe yakın bir değer ortaya koyması PVsyst simülasyon programının güvenilir bir yazılım olduğunu göstermektedir. Santral kurulum öncesinde hazırlanacak fizibilite raporlarında PVsyst gibi simülasyon programlarına yer verilmesi konu hakkında gerçeğe yakın tahminler oluşturduğundan yatırımcıyı doğru yönlendirecektir.

Çalışma; Kilis ili için üç santralin üç yıllık üretim verilerinin analizi konusunda öncü durumdadır. Dolayısıyla bu çalışma; Kilis ilinde fotovoltaik enerji santralleri konusunda yatırım yapmayı düşünen kişi ve/veya kurumlara yol gösterici olma hususunda önemli bir yere sahiptir. Yapılan analiz, farklı simülasyon programlarında, diğer coğrafi bölgelerde veya farklı illerde tekrarlanarak geliştirilebilir ve yatırım konusunda daha hassas veriler elde edilebilir. Hatta farklı simülasyon programlarında durum mukayesesi de yapılabilir.

\section{Yazar(lar)ın Katkıları}

MS: ve MN analiz çalışmalarını yaptı ve birlikte makaleyi yazdı. Her iki yazar da makalenin son halini okudu ve onayladi. 


\section{Çıkar Çatışması}

Yazarlar, çıkar çatışması olmadığını beyan eder.

\section{Kaynaklar}

[1]. Ayım Otu B., Kuncan M., Horoz S., "Research on renewable energy (solar) in Ghana", Uluslararası Bilim ve Mühendislik Sempozyumu, 2019, Siirt, 1018-1029.

[2]. Çiftçi S., Solak M., Kuncan M., "Powered by the sun: designing and analyzing technical and economic aspects of a school sustained by photovoltaics", Journal of Mechatronics and Artificial Intelligence in Engineering, 2020, 1(1): 21-32

[3]. İzgi E., Özcan Ö., "Şebekeye bağlı fotovoltaik çatı sisteminin karşılaştırmalı performans analizi”,KSÜ Mühendislik Bilimleri Dergisi, 2020, 23(3): 127-140.

[4]. Erdoğan N., "Yenilenebilir enerjiye yönelik teşvikler ile yenilenebilir enerji üretimi arasındaki etkileşim ve finansal yansımaları", Yüksek lisans tezi, Cumhuriyet Üniversitesi, (2020).

[5]. Demiryürek H.K., Arifoğlu U., Boat M., "Lebit enerji güneş santralinin PVsyst programı ile analizi”, BEÜ Fen Bilimleri Dergisi, 2020, 9(3): 1351-1363.

[6]. Yılmaz Ş., "Kahramanmaraş il merkezi koşullarında optimum enerji verimliliğine sahip fotovoltaik temelli bir elektrik jeneratörünün modellenmesi ve gerçekleştirilmesi”, Doktora tezi, Kahramanmaraş Sütçü İmam Üniversitesi, (2015).

[7]. Küçükgöze O.M., "Erzincan ilinde güneş enerjili Elektrik üretim sisteminin ekonomik analizi”, Yüksek lisans tezi, Erzincan Üniversitesi, (2016).

[8]. Kandilli İ., Minaz M.R., Kuncan M., Kuncan F., "Güneş enerjisiyle arabalarda soğutma ve 1sitma sisteminin tasarımı", International Conference on Multidisciplinary, Science, Engineering and Technology (IMESET'17 Bitlis), 365-370, (2017).

[9]. Özyiğit F.Y, Sarı V., "Sivas Cumhuriyet Üniversitesi yerleşkesinde güneş enerjisi santralinin ekonomik analizi”, Dokuz Eylül Üniversitesi Mühendislik Fakültesi Fen ve Mühendislik Dergisi, 2020, 22(65): 517-526.

[10]. https://www.enerji.gov.tr/tr-TR/sayfalar/Gunes, Erişim tarihi Kasım 29, 2019.

[11]. Eremkere M., Aktaş T., "Tekirdağ Bağcılık Araştırma Enstitüsü Üzüm Suyu İşleme Tesis çatısına uygulanabilecek fotovoltaik tasarımların teknik, ekonomik ve çevresel açılardan analizi”, El-Cezerî Journal of Science and Engineering, 2020, 7(1): 275-294.

[12]. https://www.teias.gov.tr/tr-TR/turkiye-elektrik-uretim-iletim-istatistiikleri, Erişim tarihi Aralık 01,2020.

[13]. Tozlu C., "Muğla Üniversitesinde kurulu şebekeye bağlı fotovoltaik güç sistemlerinin performans analizi”, Yüksek lisans tezi, Muğla Üniversitesi, (2004).

[14]. Akcan E., Kuncan M., Minaz M.R., "PVsyst yazılımı ile 30 kW şebekeye bağlı fotovoltaik sisteminin modellenmesi ve simülasyonu", Avrupa Bilim ve Teknoloji Dergisi, 2020, 18: 248-261.

[15]. Sülü M., "Fotovoltaik güç santrallerinde enerji kaybı ve verimlilik entegrasyonu”, Yüksek lisans tezi, Kilis 7 Aralık Üniversitesi, (2019).

[16]. Babatunde A.A., Abbasoğlu S., "Evaluation of field data and simulation results of a photovoltaic system in countries with high solar radiation", Turkish Journal of Electrical Engineering \& Computer Sciences TÜBİTAK, 2015, 23: 1608-1618. 
[17]. Aksangör N.N., "Ankara şartlarında bir fotovoltaik sistemin PVsyst programı yardımı ile prformans analizi”, Yüksek lisans tezi, Gazi Üniversitesi, (2019).

[18]. Tekkale G., “Türkiye'nin çeşitli illerinde yapılacak arazi tipi lisansız güneş enerjisi santrali yatırımlarının teknik ve finansal analizi”, Yüksek lisans tezi, İstanbul Teknik Üniversitesi, (2018).

[19]. Girgin, M.H., "Bir fotovoltaik güneş enerjisi santralinin fizibilitesi, Karaman bölgesinde MW'lık güneş enerjisi santrali için enerji üretim değerlendirmesi ve ekonomik analizi", Yüksek lisans tezi, İstanbul Teknik Üniversitesi, (2011).

[20]. https://www.kilis.gov.tr/ cografi-yapi, Erişim tarihi Ekim 04, 2020.

[21]. https://www.investinkilis.gov.tr/ Yenilenebilir-Enerji-İcerik-84.html., Erişim tarihi Ekim 04, 2020.

[22]. https://www.gepa.enerji.gov.tr/MyCalculator/pages/79.aspx, Erişim tarihi Aralık 01, 2020.

[23]. Bulut N., Kuncan M., Horoz S., "Türkiye'de güneş enerjisinin kullanım alanları ve Siirt güneş enerjisi potansiyeli”, Ahtamara I. Uluslararası Multidisipliner Çalışmalar Kongresi, Van, 1315-1319, (2018).

[24]. Sarı V., Özyiğit F.Y., "Sivas ilinin farklı ilçelerinde şebeke bağlantılı güneş enerji santrallerinin tasarımı ve analizi", Avrupa Bilim ve Teknoloji Dergisi, 2020, 20: 425-437.

[25]. Yıldız A., Yıldırız E., "Düzce çevresi su temini uygulamalarında kullanılacak $15 \mathrm{kWp}$ fotovoltaik sistemin fayda-maliyet analizi”, Emo Bilimsel Dergi, 2019, 9(2): 53-60.

[26]. https://www.mgm. gov.tr/kurumici/radyasyon_iller.aspx?il=kilis, Erişim tarihi Aralık 03, 2020.

[27]. Haydaroğlu C., Gümüş B., "Dicle Üniversitesi güneş enerjisi santralinin PVsyst ile simülasyonu ve performans parametrelerinin değerlendirilmesi”, Dicle Ünivesitesi Mühendislik Fakültesi Mühendislik Dergisi, 2016, 7(3): 491-500.

[28]. Erdoğan Y., Dinçler T., Kuncan M., Ertunç M.H., "Güneş panelleri için yüksek verimli maksimum güç noktası izleyicisi (MPPT) tasarımı", TOK 2014 Bildiri Kitabı, Kocaeli, 10551060, (2014).

[29]. Çekirdek M., "Fotovoltaik güç santrallerinin tekno-ekonomik analizi: Türkiye Örneği", Yüksek lisans tezi, Dokuz Eylül Üniversitesi, (2017).

[30]. Tanış Z., "Elazı̆g ilinde yer alan şebekeye bağlı fotovoltaik güneş enerjisi santralinin performans analizi”, Yüksek lisans, Yıldız Teknik Üniversitesi, (2019).

[31]. Çınaroğlu M.S., Nalbantoğlu M., "Kilis İlinde bulunan on - grid bir güneş enerji santralinin PVsyst programı ile performans analizi", 5th Intenational Engineering and Natural Sciences Conference (INESEG), Diyarbakır, 199-208, (2020).

[32]. Bulut K., Ghaderi D., "Maximum power point tracking by the small-signal-based PI and fuzy logic controller approaches for a two-stage switched-capacitor DC-DC power boost converter; applicable for photovoltaic utilizations”, El-Cezerî Journal of Science and Engineering, 2020, 7(3): 1167-1190.

[33]. Pakma N., “Batman'da 1 MW'lık fotovoltaik enerji sisteminin tasarlanması”, Yüksek lisans tezi, Batman Üniversitesi, (2016).

[34]. Dülger G., Çubukçu M., Schmid A., "Fotovoltaik modüllerin güç ölçümü belirsizliklerinin analizi”, V.Elektrik Tesisat Ulusal Kongre ve Sergi Bildirileri, (2017). 
[35]. Koirala B.P., Sahan B., Henze N., "Study on MPP mismatch losses in photovoltaic applications", 24th European Photovoltaic Solar Energy Conference and Exhibition (EU PVSEC), Hamburg, Germany, 3727-3733, (2009).

[36]. Çıngı A., "Güneş enerjisi elektrik santrallerinde kullanılan fotovoltaik panellerin enerji verimliliklerinin belirlenmesi”, Yüksek lisans tezi, Kilis 7 Aralık Üniversitesi, (2019).

[37]. Romaliya J.V., "Performance evaluation of grid-connected solar photovoltaic plant using PVsyst software", Journal of Emerging Technologies and Innovative Research (JETIR), 2015, 2(2): 372-378.

[38]. Kırbaş İ., Çiftci A., "Feasibility study of a solar power plant installation: a case study of lake Burdur, Turkey", El-Cezerî Journal of Science and Engineering, 2019, 6(3): 830-835.

[39]. Akkaş Ö.P., Çam E., "Optimal operation of a virtual power plant in a day-ahead market considering uncertainties of renewable generation and risk evaluation", El-Cezerî Journal of Science and Engineering, 2020, 7(2): 448-460.

[40]. Dağoğlu Ö., “Toplu konutlarda fotovoltaik sistem kullanımlarının farklı iklim bölgelerine göre değerlendirilmesi”, Yüksek lisans tezi, Fırat Üniversitesi, (2019).

[41]. Irwan Y.M., Amelia A.R., Irwanto M., Fareq M., Leow W.Z., Gomesh N., Safwatı I., "Standalone photovoltaic (SAPV) system assessment using PVsyst sofware", Energy Procedia, 2015, 79: 596-603.

[42]. Kilc1 O., Koklu M., "The importance of fixed and variable angle in solar power plants analysis", International Journal of Applied Mathematics, 2019, 7(4): 75-83.

[43]. Özden T., Karaveli A., Akınoğlu B., "Comparison of the models for solar photovoltaic system performance calculations for Ankara (Middle Anatolia)", Avrupa Bilim ve Teknoloji Dergisi, 2020, 18: 54-60. 